\title{
Business Forecasting Imperatives in a Depressed Economy: A Nigeria Case
}

\author{
Frank Alaba Ogedengbe ${ }^{1}$, Esther Ogedengbe ${ }^{2}$, Clement Osigwe Okhakhu $^{1}$, \\ Donald Ozemenbhoya Ewanlen ${ }^{3}$ \\ ${ }^{1}$ Department of Business Administration \& Management, School of Business Studies, Auchi Polytechnic, Auchi, Edo State, Nigeria \\ ${ }^{2}$ Department of Humanities, School of General Studies Auchi Polytechnic, Auchi Edo State, Nigeria \\ ${ }^{3}$ Department of Marketing and Entrepreneurship, Federal University, Otuoke Bayesla State, Nigeria
}

Email address:

ogedengbefrank@auchipoly.edu.ng (F. A. Ogedengbe)

\section{To cite this article:}

Frank Alaba Ogedengbe, Esther Ogedengbe, Clement Osigwe Okhakhu, Donald Ozemenbhoya Ewanlen. Business Forecasting Imperatives in a Depressed Economy: A Nigeria Case. American Journal of Operations Management and Information Systems.

Vol. 3, No. 2, 2018, pp. 46-51. doi: 10.11648/j.ajomis.20180302.12

Received: April 26, 2018; Accepted: May 15, 2018; Published: June 25, 2018

\begin{abstract}
This study, business forecasting imperatives in a depressed economy: The Nigeria case takes a careful and cursory but scholarly look at the importance of Business Forecasting in the management of Business Enterprises, especially in a depressed economy like Nigeria's. The world has become dynamic and uncertain and the business world is not left out in the change that is sweeping globally across all spheres, especially in the management of business enterprises. Since the business environment and terrain have become so dynamic, uncertain and given to change as it is now, scientific business forecasting can no longer remain an option but a sine qua non in the management of business enterprises, if these enterprises and businesses are to escape and survive the mucky and slippery waters of competition, change, uncertainty and dynamism. This study employed the literature study methodology in its approach. The study systematically brings out and highlights the business forecasting techniques and the drawbacks associated with the usage of these techniques. It also examines the importance of business forecasting to business enterprise, and business forecasting nuggets managers need to observe and adhere to in forecasting. The study concludes that urgent and concerted consideration and attention be given to scientific business forecasting in the management of business enterprises to bring the economy out of the woods and troubled waters.
\end{abstract}

Keywords: Scientific Business Forecasting, Depressed Economy, Business Decisions, Nigeria

\section{Introduction}

The world has become dynamic and uncertain as the words dynamic and uncertain themselves. The business world is not left behind in the change that is sweeping globally across all spheres, especially in the management of business enterprises. The business environment and terrain have become so dynamic, uncertain and given to change to the extent that scientific business forecasting can no longer remain just an option but a sine qua non in the daily management of business enterprises. If these enterprises and businesses are to escape or survive the mucky waters of competition, change, uncertainty and dynamism, then urgent attention must be given to scientific and quantitative business forecasting.

The things that hitherto were exceptions rather than the rules are fast displacing and replacing the rules both in business, health, government and management, as well as almost every other sphere of human endeavour. Business forecasting as a tool for budgeting, planning, and estimating future growth and trends, is defined in the most simplest terms as, attempt to predict future results or outcomes based on past events, experiences and management insight, by using scientific and quantitative methods like exponential smoothening, trend fitting, regression and correlation analyses $[1,2]$.

The dynamic and uncertain nature of business and business environment, especially in the less developed and developing countries of the world, like Nigeria, where businesses are most often subsistence, small and mediums scale in nature, requires more of both management and leadership skills from both managers and employees. These call for urgent review 
and immediate action to be taken in order to change the way things are done and how businesses are run, with a view to avoiding pitfalls, failure, collapse or closure of such businesses. One of such ways is to specifically look in the direction and area of scientific business forecasting [2].

This study seeks to expand the frontiers of scientific and quantitative business forecasting with specific reference to their applications in business and management as a means of avoiding business pitfalls, collapse, closure, failure and death of such businesses. It seeks also to present the imperatives of business forecasting for operating businesses in a depressed economy.

Forecasting is not a very palatable or easy endeavour to embark upon, especially when forecasting results or outcomes are not quite where everyone wants them to be. Coincidentally, investment in the forecasting function is neither a guarantee for better forecasts nor a prevention of business eventualities. But when issues that are fundamental to an organisation's forecasting are well taken care off, then investing in forecasting activities or function will be worth the while.

This study identifies and presents several basic and fundamental issues that should be of concern to organizations wishing to create a new forecasting function and to those that want to improve those they already have and are used to [3, 4].

\section{Forecasting in Business Enterprise Management}

Forecasting is a planning tool that helps management in its attempts to cope with the uncertainty of the future, relying mainly on data from the past and present and analysis of trends. Forecasting starts with certain assumptions based on the management's experience, knowledge and judgement. These estimates are projected into the coming months or years using one or more techniques. Forecasting can be regarded as the process of making predictions of the future based on past and present data and most commonly by analysis of trends. Both might refer to formal statistical methods employing time series, cross sectional or longitudinal data, or alternatively to less formal judgmental methods $[5,6]$.

Forecasting is a decision making tool employed by managers and business enterprises in budgeting, planning and estimating and determining future growth and trends. Forecasting is the attempt to predict future results or outcomes based on past events and management insight. It involves the use of historical data to determine the direction of future trends and business performances and profitability. Businesses utilize forecasting to determine how to allocate their budgets or plan for anticipated expenses for an upcoming period or season. This is typically based on the projected demand for the goods, services and results they offer [7].

Business forecasting is an estimate or prediction of future developments in business such as sales, expenditures, demand and profits [6]. Given the wide swings in economic activity and the drastic effects these fluctuations can have on profit margins, it is not surprising that business forecasting is emerging as an important aspect of corporate planning. Forecasting has become an invaluable tool for business people to anticipate economic trends and prepare themselves either to benefit from or to counteract them. If business enterprises foresee an economic downturn, they can cut down on their inventories, production quotas, and hiring. If, on the hand, an economic boom seems probable, such business enterprises can take relevant measures to attain the maximum benefit from same. Good business forecasts help managers, business owners and investors adapt to a changing and prevailing economic situations [8-10].

Business enterprises need regular forecast like, weekly, monthly or annual forecasts. A major important reason business owners, planners or forecasters prefer the annual forecast is that sudden changes in the economic climate can play havoc with the weekly, monthly or quarter-to-quarter measurements. A major pitfall in business forecasting is to over promise and under deliver with forecasting results. Forecasting can predict many things with impressive accuracy, but there are also always going to be factors one cannot account for. Such unaccounted for factors can render such forecasts and forecast results and outcomes meaningless.

\subsection{Business Forecasting Techniques}

To adequately prepare for and guide against eventualities and vagaries of business prevalent in business operations and environment, every manager would like to know the exact nature of future events. This will enable them to accordingly take action or plan their actions when they have ample and sufficient time to implement such plans. How effective management plans are depends upon the level of accuracy with which the future events are known and predicted. Business managers plan for the future irrespective of the fact, whether future events are exactly known or not. Business enterprises require various forecasts, such as, short, medium and long term forecasts, depending on the prevailing specific application or situation. The short term forecasts are needed for scheduling of personnel, production and transportation. As part of the scheduling process, forecasts of demand are often also required [1], [11] [12] [1] states that the medium term forecasts are needed to determine future resource requirements in order to purchase raw materials, hire personnel, or buy machinery and equipment. He further states that the long term forecasts are used in strategic planning. Such forecasts take into cognisance and account market opportunities, environmental factors and internal resources. Managers and business enterprises need to develop a forecasting system that involve several approaches to predicting economic and business events, circumstances, conditions and situations that are prevalent at the time. This naturally requires the development of expertise in identifying forecasting problems, applying a range of forecasting methods and techniques, selecting appropriate methodology 
or procedures for each problem, and evaluating and refining forecasting methods over time. It is also important to have a very strong organizational support for the use of formal forecasting techniques.

Usually, economic forecasts predict sundry economic indicators like money supply, inflation rates, and interest rates. Also technological forecasts predict rates of technological progress and innovation resulting from research and development. On the other hand demand forecasts predict the future demand for products, services or results. Since virtually all the operations management decisions in both the strategic category and the tactical category, require as input a good estimate of future demand, this is the type of forecasting that is mostly emphasized in business forecasting [1], [6], [11], [12].

Business forecasting techniques are classified and enumerated under the qualitative and quantitative forecasting methodologies or techniques. These methodologies are as listed hereunder.

\subsection{Qualitative Business Forecasting Techniques}

Qualitative business forecasting methods are forecasting techniques based on the forecaster's or manager's judgments, opinions, intuition, emotions, or personal experiences and sentiments acquired through training or over time. Qualitative business forecasting are usually very subjective and do not rely on any rigorous mathematical rules, theory, assumptions or computations. Highlighted and enumerated below are some common qualitative businesses forecasting techniques.

Grass Roots: this type of forecasting techniques is by adding successively from the bottom to the top. The forecaster or manager assumes that the person closest to the customer or the end users of the product knows its future needs best. This may not always true, but in many instances it has proved to be a valid assumption, and has therefore become the basis for this method. Forecasts at this bottom level are summed and given to the next higher level.

Market Research: market research uses surveys, questionnaires and interviews to gather data and information from consumers, relating to their likes and dislikes about existing products, services and results and what they expect from future products or services. The results from such research become a basis for forecasting the demand for such products, services and or results. This type of research is used mostly for product research in the sense of looking for new product ideas, likes and dislikes about existing products, which competitive products within a particular class are preferred.

Panel Consensus: The panel consensus business forecasting technique or methodology, a qualitative business forecasting technique, brings together the internal members or experts from the various levels of the organization to have an open discussion about an activity or a product, service or result the organization desires to work on. This is with the intention of getting a better forecast, as group forecast should be better than individual forecast. Members are allowed to give their opinions, suggestions and decisions and the meeting would normally be concluded when a consensus has been reached. Panel forecasts are developed through open meetings with free exchange of ideas from all levels of management and individuals. Whereas this method relies very much on experience and opinion, it gives opportunity to a large number of persons to make contribution to the final agreement reached by the group. This forecasting technique is most suited for tactical decision making in the organization [14].

Historical Analogy: historical analogy is a judgmental and qualitative business forecasting technique based on identifying and analysing the history of the performance of a products, service or result, over time, which is analogous to a current or present situation of such product, service or result. Such past patterns are used to predict or forecast the future behaviour of such product, service or result. The historical analogy method is used for forecasting the demand for products, services or results under the circumstances that no past demand data are available. This is especially true if the product happens to be new for the organization.

Delphi Method: The Delphi method is a forecasting method based on the results of questionnaires sent to a panel of experts. Several rounds of questionnaires are sent out, and the anonymous responses are aggregated and shared with the group after each round. The experts are allowed to adjust their answers in subsequent rounds. Since multiple rounds of questions are asked and the panel is told what the group thinks as a whole, the Delphi method seeks to reach the correct response through consensus. This technique came into being to try to correct impairments to free exchange. When decisions in forecasting are at a broader, higher level, like when introducing a new product line or concerning strategic product decisions such as new marketing areas, the term executive judgment is generally used. The term is self explanatory a higher level of management is involved. As mentioned under panel consensus, a statement or opinion of a higher level person will likely be weighted more than that of a lower level person.

\section{Quantitative Business Forecasting Techniques}

[9] Defines quantitative business forecasting as statistical techniques for making projections about the future which use numerical and prior experience to predict upcoming events. They are forecasting techniques that are based on Scientific, Mathematical or Statistical models, and are objective in nature. They rely heavily on mathematical and statistical assumptions and computation. Highlighted and enumerated below are some common quantitative businesses forecasting techniques.

\subsection{Business Forecasting Nuggets}

Business forecasting is as important and critical as planning is to business enterprises, especially in times of economic depression and downturn, currently being 
experienced in some countries of Africa like Nigeria. Below are some very useful and important nuggets and tips on how to go about business forecasting accurately and effectively [13-16].

Do not ignore forecasting: Forecasting can seem quite an easy thing to put off, put aside or indeed not to do at all. It is very important an advice that forecasting should not be ignored in business management.

Know what you are into: You need to know and understand what you are into when forecasting business performance. When one has a clear understanding of what one is into, the task of forecasting becomes easier.

Know who is involved: While forecasting should be done as standard practice, sometimes it is also necessary for specific reasons such as raising finance from the bank or from external investors. The underlying process is the same, but the communication is different depending on the audience or the target.

Know your target: Forecasting should not be based on your business performance alone, but also that of the market around your business, like the competitors, creditors and debtors to mention a few. One needs to know the customer base and competition inside out.

Need for flexibility: While forecasting is difficult in the best of times, these are not the best of times. There need to be flexibility built into any business forecast system. The further ahead that you forecast the less meaningful forecasting becomes.

Make use of all available tools: There are specific types of business forecasting tools and software available. It is always better to use simple and less complex methodologies in forecasting.

Be realistic: When forecasting, especially for the benefit of an external investor, there is a natural tendency towards optimism. You need to forecast not just the expectations of the best scenario but also the worst scenario if sales go the unexpected side.

Control your credit: Poor credit control and management can throw your forecasts off dramatically. As the business grows, you can deal with small lumps as they are naturally smoothed over by the sheer scale of the business.

Know your interest rates: Small businesses need to keep abreast of the various interest rates they pay, and forecast accordingly. Businesses will typically have an overdraft, a loan, some hire purchase on equipment, but they do not necessarily compare the interest rates that they have.

Avoid excitement: Despite the importance of forecasting, do not forget that the most important thing is actually running your business in a proper manner. Be customer focused and people oriented in decision making all the time and do not let your eye off your focus, which is customers' satisfactions. Respect ethics and the rules of the game.

\subsection{Imperatives of Business Forecasting}

Business forecasting is an imperative in modern day business enterprises' management. This goes to say that the importance of business forecasting cannot be over emphasized in the management of business enterprises today. The following are some of the growing importance of business forecasting. The list is not exhaustive [18-21].

Promotion of new business: Forecasting is of utmost importance in setting up a new business. It is not an easy task to start a new business as starting a new business is full of uncertainties and risks. With the help of forecasting the promoter or promoters can find out whether they can succeed in the new business, whether they can face the existing competition and what the possibility of creating demand for the proposed product will be. After discovering the business opportunity, they will see the possibilities of assembling men, money, materials and other resources. The success of a business unit depends upon how sound the forecasting is. Proper forecasting will help to minimize the role of luck or chance in determining business success or failure. A successful promoter is also the prophet of economic conditions.

Estimation of financial requirements: The importance of forecasting cannot be ignored in estimating the financial requirements of a business enterprise. Efficient utilization of capital is a delicate issue before any management. No business can survive without adequate capital. But adequacy of either fixed or working capital depends entirely on sound financial forecasting. Financial estimates can be calculated in the light of probable sales and cost thereof. How much capital is needed for operations, expansion, development, to mention a few, depend upon accurate financial forecasting.

Smooth and continuous working of the enterprise: Forecasting of earnings ensures smooth and continuous working, running or operation of an enterprise, particularly the newly established ones. Through forecasting, these enterprises can estimate their expected production volume, sales and profits or losses. The objective of a forecast is to reduce drastically, in black and white the details of the workings of an enterprise. By forecasting on a regular basis, it forces companies to continually think about their future and where their company is headed. This will allow them to foresee changing market trends and keep up with the competition.

Astuteness of management decisions: The correctness of management decisions, to a great extent, depends upon accurate forecasting. Administration is essentially a decision making process and authority has responsibility for making decisions and for ascertaining that the decisions made are carried out. In business, whether the enterprise is large or small, changes in conditions occur; shifts in personnel take place, unforeseen contingencies arise. Moreover, just to get the wheels started and to keep them running, decisions must be made. This shows that the decision making process continues throughout the life of the business enterprise. Forecasting plays an important role in various fields of the enterprise. As in the case of production planning, managers have to decide what to produce and with what resources to effect such production. Forecasting is considered as the indispensable component of business, because it helps management to take correct decisions. 
Success in business: The accurate forecasting of sales helps to procure necessary raw materials on the basis of which many business activities are undertaken. The accurate sales forecasting becomes the basis for several other budgets. In the absence of accurate sales forecasting, it is difficult to decide as to how much production should be done. The budgets of other departments depend upon the compilations based on the sales forecasts and the accuracy of these budgets also depends upon correctness of sales forecasting. Thus, the success of a business unit depends on the accurate forecasting by other constituent departments.

Plan and Strategy Formulation: The importance of correct forecasting is apparent from the key role it plays in planning and strategy formulation. It should not go unaccounted that forecasting is an essential element in planning since planning premises include some forecasts. There are forecast data of a factual nature, having enormous implication on sound premises. Undoubtedly, forecasting is a prelude to planning and indeed it is the foundation on which planning stands. Planning under all circumstances and in all occasions involves a good deal of forecasting. Forecasting is appraising the future in the light of existing conditions, circumstances and environment. Forecasting and planning are closely related. Adequate planning, no matter whether it is overall or sectoral, short term or long term or strategic, largely depends on forecasting.

Cooperation and coordination: Forecasting is neither the job for one man nor a one man show. It needs proper coordination and cooperation of all departmental heads in an organization or firm. By bringing participation of all concerned in the process of forecasting, team spirit and coordination is automatically encouraged. The act of forecasting is of great benefit to all who take part in the process, and is the best means of ensuring adaptability to changing circumstances. The collaboration of all concerned leads to united front, understanding of the reasons for decisions taken and broadened outlook to decision making.

Complete Control: Forecasting provides the information which help in the achievement of effective control. The managers become aware of their weaknesses during forecasting and through implementing better effective control they can overcome these identified weaknesses.

Happy Customers: In order to keep your customers satisfied you need to provide them with the product they want when they want it. This advantage of forecasting in business will help predict product demand so that enough products are available to fulfil customer orders. By using business forecasting to look ahead, enterprises are able to make sure they always have product available for the customers to purchase. If the shelves are bare for any length of time, a customer is extremely likely to try another brand.

Learn From The Past: Looking at what has happened in the past can help companies predict what will happen in the future, thereby making the company stronger and most likely more profitable. Enterprises look at past sales and trends and use that data to try and predict the future.

Personnel Cost Saving: Forecasting in business allows companies to predict the product needs of their customers.
From here a company can use this data to accurately determine how many employees they will need to have on hand to meet the required level of production. Many wineries have fairly small profit margins, so it is important to make sure they have the correct amount of staff on hand and are not employing too many people.

Remain Competitive: A business that does not use forecasting techniques will likely succumb to their competitors in a short time. Having a general idea of what sales to expect in the following period is very important. This will help a company prepare to meet customers' demand.

Helps Prepare for a Drop in Sales: A drop in sales is never a good thing for a company, however, this advantage of forecasting in business reveals sales drops which in turn, can be recognized and dealt with quickly. When enterprises have forecast a drop in sales they will slow down production. This means having less stock in their store at any given time, and also less finished goods inventory on hand at their various facilities $[1,7,22]$

\section{Conclusion}

Forecasting does not provide you with a crystal ball to see exactly what will happen to the market and your company over the coming years, but it will help give you a general idea. This will provide you with a sense of direction which will allow your company to get the most out of the marketplace. Predicting the future can be very difficult. By forecasting, one can predict future trends and then change their company objectives to achieve success even in a depressed economy.

Business forecasting is an estimate or prediction of future developments in business such as sales, expenditures and profits. Given the wide swings in economic activity and the drastic effects these fluctuations can have on profit margins, it is not surprising that business forecasting has emerged as one of the most important aspects of corporate planning. It has become an invaluable tool for business people to anticipate economic trends and prepare themselves either to benefit from or to counteract them. If, for instance, business people envision an economic downturn, they can cut back on their inventories, production quotas, and hiring. If, on the contrary, an economic boom seems probable, those same business people can take necessary measures to attain the maximum benefit from it. Good business forecasts help business owners and managers adapt to a changing economy.

\section{References}

[1] Dhaval, S.

http://www.businessmanagementideas.com/businessforecasting/top-6-methods-of- business-forecasting/3952 retrieved on January 20, 2018.

[2] Ogedengbe, F. A (2016). Stochastic Approach to Debt Management in Nigeria Banking Sector. Unpublished PhD thesis submitted to the Department of Business Administration, University of Benin, Benin City, Nigeria. 
[3] Ajonbadi, H. A. (2000). Applied Business Management Theory. Mcdonald Evans: London.

[4] Armstrong, J. S., Brodie, R. \& McLntyre, S. (1987). Forecasting Methods for marketing, International Journal of Forecasting, 3, 355-376.

[5] BusinessDictionary (2017a). http://www.businessdictionary.com/definition/forecasting.html

[6] Encyclopedia.com (2017). http://www.encyclopedia.com/social-sciences-andlaw/economics- business-and-labor/economics-terms-andconcepts/business

[7] Crosby, J. V. (2000). Cycles, Trends, and Turning Points: Practical Marketing and Sales Forecasting Techniques. NTC Publishing.

[8] Chase, C. W. Jr. (2000). Composite Forecasting: Combining Forecasts for Improved Accuracy. Journal of Business Forecasting.

[9] Aston, A. and Weber, J. (2006). "The Worst Isn't Over: Smarter science is helping companies and insurers plan for hurricanes. The Bad News: This year could be another doozy." Business Week, Jan 16,

[10] BusinessDictionary. (2017b).

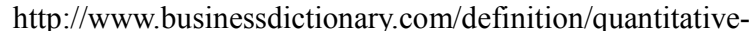
forecasting.html

[11] Mentzer, J. T., \& Carol C. B. (1998). Sales Forecasting Management: Understanding the Techniques, Systems, and Management of the Sales Forecasting Process. Sage.
[12] Mentzer, J. T. \& Mark A. M. (2004). Sales Forecasting Management. Sage Publications, Inc.

[13] Lancaster, G. A. \& R. A. Lomas, 1985, Forecasting for sales and material management Macmillan, London 3-3/4

[14] Henry, P. \& Joseph, A. (1987). Callanan. Sales Management and Motivation. Franklin Watts.

[15] Hughes, M. C. (2001). Forecasting Practice: Organizational Issues, The Journal of the Operational Research Society, 52, (2):143-149.

[16] Lucey, T, (2002). Quantitative Techniques, 6th edition, London: Continuum Book Power/ELST.

[17] Green, K. C., Armstrong, J. S., \& Graefe, A. (2007). Methods to Elicit Forecasts from Groups: Delphi and Prediction Markets Compared. Foresight, 8, 17-20.

[18] Evans, M. (2002). Practical Business Forecasting. Blackwell Publishing. Sage.

[19] Gaber, T. J, Goldenberg, B. L., \& Eitan M. (2004). From Density to Destiny: Using spatial dimension of sales data for early prediction of new product success. Marketing Science.

[20] Gray, A. (2005). How Forecasting Can Help the Bottom Line. Fairfield County Business Journal.

[21] Engerman, S. (2005). On the Accuracy of Some Past and Present Forecasts. International Monetary Fund Staff Papers.

[22] Churchill, Jr., Ford, N. M., Walker, Jr., O. C., Johnston, M. W., \& Tanner, Jr., J. F. (2000). Sales Force Management, 6th ed., Boston: Irwin McGraw-Hill. 